\title{
PROFESSOR NORBERT PETERS 10 July 1942-4 July 2015
}

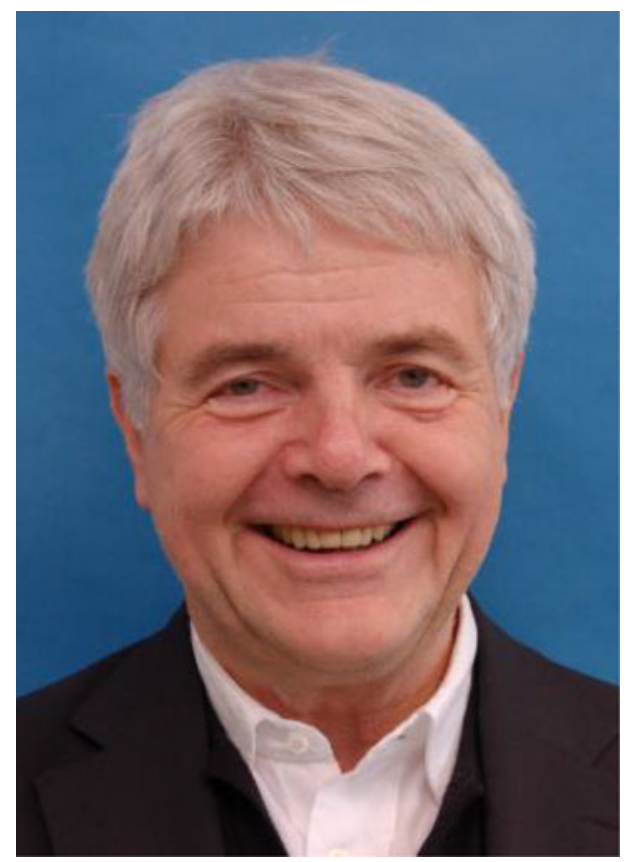

Norbert Peters passed away on 4 July 2015 at the age of 72 . He was on vacation with his family in France when he experienced a sudden and severe heart attack. Medical help came too late, and he died just two days later. His death was a shock for many of us who knew him well. He was seemingly in great health, lively, sharp as ever, and always full of ideas and big plans; he was in a good mood, scientifically very active, and he had not lost any of his unbelievable energy and unstoppable scientific curiosity.

Norbert was born 10 July 1942 in Linz in Austria. He grew up in Dortmund, Germany and finished high school there in 1962, having spent one year at a Florida high school in the United States. Before starting his university studies he worked for six months in a program of practical engineering within a German-Indian collaboration at the Rourkela steel plant in India. Norbert studied mechanical engineering at the Technical University of Karlsruhe and received a pre-diploma in 1965. Subsequently, he continued his studies at the Technical University of Berlin and was awarded a diploma in chemical engineering there in 1968. He then studied Economics in Paris (Bourse d'Etat Français during one year at the Ecole Practique des Hautes Etudes, Paris, France), where he also published a paper in 1969 on French poetry. He then returned to Berlin, where he received his $\mathrm{PhD}$ in 1971 for his work on chemically reacting boundary layers and completed his habilitation in 1975, on the topic Thermodynamics and the Theory of Chemically Reacting Flows, having advanced from a Research Assistant to an Assistant Professor. Norbert moved to RWTH Aachen University in 1976 as a Professor within the Institute for Mechanics and became a Full Professor and Director of the Institute for Applied Mechanics 
in 1987. Through Norbert's efforts, this institute recently became the Institute for Combustion Technology. In 2001, he accepted a one-year full-professor appointment at Stanford University but returned to Aachen after that. Although he retired as Director of the Institute for Combustion Technology at Aachen University in 2013, being succeeded by Heinz Pitsch, he continued his research and teaching in the institute, unabated.

Norbert has clearly left a mark in fluid mechanics and combustion science with his seminal and foundational contributions to the theory of flames and flame asymptotics, chemical kinetics, turbulent combustion, and the theory of turbulence. While his research included experiments, his focus was on theory and simulation. This research was always characterized by a deep physical understanding, engineering intuition, and the application of systematic mathematics-based analysis; his theoretical work was generally based on first principles, and it was always intended to result in practical models for simulation and analysis of real technical flow and combustion systems.

In the 1990s, Norbert developed the theory for turbulence-flame interactions, models for the turbulent burning velocities, and numerical simulation techniques based on level sets, resulting in the so-called $G$-equation, which he clarified and extended for use in turbulent-combustion modelling. One of his major findings was what he called the thin-reaction-zones regime, a previously unknown regime of premixed turbulent combustion, where reaction zones remain intact but turbulence affects the transport, a regime in which most practical applications reside. In 2000 he published his book entitled Turbulent Combustion, a clear, concise and complete exposition of that subject, treating diffusion and premixed as well as partially premixed flames - a book that remains today a most authoritative source of information on the topic. More recently, much of Norbert's original research has been in turbulence theory, where he introduced the concept of dissipation elements that leads to a description of small-scale turbulence, and which again has been very influential for many researchers. While this work is very fundamental, it was his trademark to use this new theory in applications, for example, in predictions of mega-knock in turbo-charged spark-ignition engines.

He was a member of both the North Rhine-Westphalian Academy of Sciences, Humanities and the Arts and the US National Academy of Engineering. Among other awards, he received the Leibniz Prize in 1990, which is the most important research award in Germany, the Hornig Memorial Award and the Arch T. Colwell Merit Award of the Society of Automotive Engineers, the Zeldovich Gold Medal from the Combustion Institute in 2002, and honorary doctoral degrees from the Université Libre de Bruxelles, the Technical University of Darmstadt, and ETH Zurich. Norbert also served as deputy editor of Combustion and Flame from 1982 to 1998, as one of the founding editors of Flow, Turbulence and Combustion from 1998 to 2002, and as associate editor of the Journal of Fluid Mechanics from 2002 to 2007.

Besides being dedicated to science, for which he had marvellous abilities, Norbert was a very decent and considerate individual who was always fun to be with. He is survived by his wife, Cordula, two young sons, and a daughter and two sons by his previous marriage.

He will be greatly missed, both as a person and as a scientist.

HEINZ PITSCH, RWTH Aachen University h.pitsch@itv.rwth-aachen.de

Forman A. Williams, University of California, San Diego faw@ucsd.edu 